\title{
An exceptional indication for bilateral thoracic paravertebral block performance in a pediatric patient
}

\author{
Emine Aysu SALVIZ, ${ }^{1}$ Necip AKMAN, ${ }^{1}$ Nükhet SiVRIKOZ, ${ }^{1}$ Kivanç DEMiR, ${ }^{2}$ Atakan AYDIN, ${ }^{2}$ Kamil Mehmet TUĞRUL'
}

To the Editor,

Paravertebral blocks (PVBs) have been previously reported for various surgical procedures in pediatric patients. ${ }^{[1-5]}$ Recently, ultrasound-guided PVBs and catheter replacement techniques have also been used effectively for pain relief after thoracic, cardiac and abdominal surgeries as an alternative to epidural analgesia in pediatric patients. ${ }^{[6-9]}$

We report a 10-year-old male patient $(30 \mathrm{~kg}, 140 \mathrm{~cm}$, ASA I) who underwent left latissimus dorsi muscle transfer (free flap) surgery under general anesthesia (GA) because of biceps brachii muscle motor weakness and atrophy occurring after oral (OPV) and inactive polio (IPV) vaccination (Figure 1). A decision was made to perform thoracic PVBs (TPVBs) bilaterally after surgery for postoperative pain management. With the patient in the right lateral decubitus posi- tion, a $10 \mathrm{MHz}$ high-frequency linear transducer (GE LOGIQ book XP, GE Healthcare, Milwaukee, WI) was placed approximately $2-2.5 \mathrm{~cm}$ lateral to the tips of the spinous processes. Sonography demonstrated the consecutive transverse processes and pleura in between. The two level TPVBs was performed using the out-of-plane technique, aiming to block the dermatomes between $\mathrm{T} 2$ and $\mathrm{T} 8$ on the left side. After negative aspiration, a total of $20 \mathrm{ml}$ of $0.125 \%$ bupivacaine was divided equally and deposited in paravertebral spaces of T3-T4 and T6-T7 while observing the pleura being moved downwards (Figure 2). Then, with the patient in the left lateral decubitus position, the same technique was used to perform a level T1 TPVBs to provide analgesia for levels C6-T2. Ten ml of $0.25 \%$ bupivacaine was injected and a 20 -gauge catheter was placed to provide vasodilation of the free flap vascular anastomosis in addition to effective pain control. The catheter was then connected to an
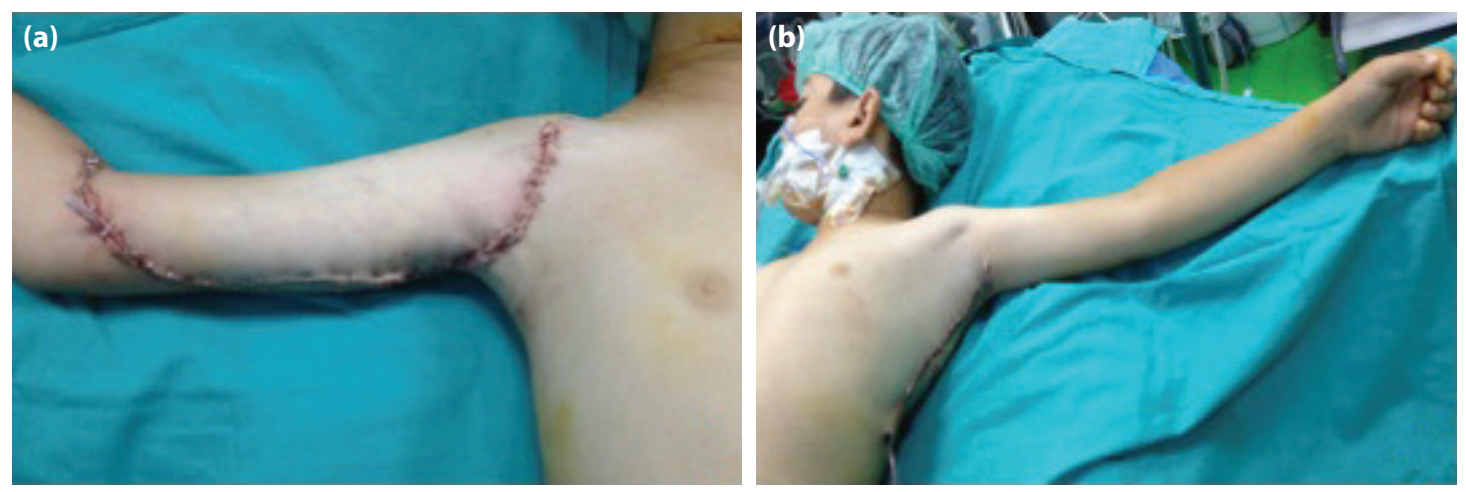

Figure 1. Transfer of left latissimus dorsi muscle to the right arm as biceps brachii muscle (free flap). (a) Latissimus dorsi excision on the left side. (b) Free flap reconstruction on the right side.

\footnotetext{
'Department of Anesthesiology and Reanimation, Istanbul University Istanbul Faculty of Medicine, Istanbul, Turkey ${ }^{2}$ Department of Plastic Surgery, Division of Hand Surgery, Istanbul University Istanbul Faculty of Medicine, Istanbul, Turkey Submitted: 24.10.2014 Accepted after revision: 01.12.2014
}

Correspondence: Dr. Emine Aysu Salviz. İstanbul Üniversitesi İstanbul Tıp Fakültesi, Anesteziyoloji ve Reanimasyon Anabilim Dalı, Millet Cad., Cerrahi Monoblok Giriş Katı, 34390 İstanbul, Turkey. Tel: +90 - 212 - 5313126 e-mail: aysusalviz@gmail.com

(c) 2015 Turkish Society of Algology 

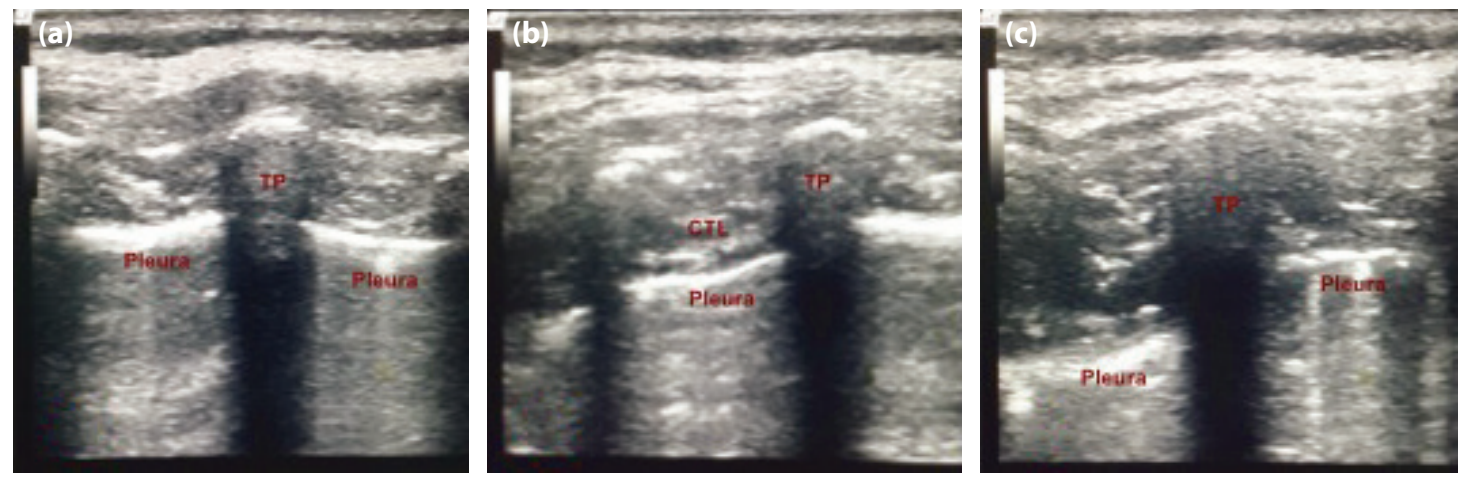

Figure 2. Ultrasound image of the consecutive thoracic paravertebral spaces obtained by placing high frequency transducer vertically, confirming optimal levels by cephalad and caudal sliding, and also local anesthetic spread. (a) Transvers processes of T3, T4 and T5, and the pleura in between. (b) Paravertebral space of T3-T4 between CTL and pleura. (c) Local anesthetic spread and downward displacement of pleura at the blocked level. TP:Transverse process, CTL: Costotransvers ligament.

infusion pump, and an infusion of $0.2 \%$ bupivacaine was initiated (basal rate of $5 \mathrm{ml} / \mathrm{h}$, bolus volume $5 \mathrm{ml}$ and lock out $30 \mathrm{~min}$ ) just after the extubation. The pain numeric rating scale (NRS) was $\leq 5$ on the left side and $\leq 2$ on the right side during the first 36 hours postoperatively. Oral paracetamol $500 \mathrm{mg}$ was used twice daily as supplemental analgesic as planned.

The patient underwent a second operation for debridement 2 days postoperatively under GA, and the catheter was removed after injecting $10 \mathrm{ml}$ of $0.25 \%$ bupivacaine at the end of surgery. His NRS was $\leq 2$ again for an additional 16 hours postoperatively without any rescue analgesic. He was stable, ambulatory, and free of IV opioids and their side effects. He expressed satisfaction with his pain control.

Epidural analgesia is considered by many to be the best method of pain relief after major surgery and is used routinely in many centres. However, it was not used in our case because of the analgesia requirement for different thoracic levels on each side. Single injection and continuous TPVBs are alternatives that may offer comparable analgesic effectiveness to thoracic epidural analgesia and a better side-effect profile.

We believe this case is important insofar as it demonstrates an exceptional indication for the use of both single injection and continuous TPVBs, and determines optimal levels for the effective blocks under ultrasound guidance.

\section{References}

1. Lönnqvist PA, Olsson GL. Paravertebral vs epidural block in children. Effects on postoperative morphine requirement after renal surgery. Acta Anaesthesiol Scand 1994;38(4):346-9.

2. Lönnqvist PA. Continuous paravertebral block in children. Initial experience. Anaesthesia 1992;47(7):607-9.

3. Shah R, Sabanathan S, Richardson J, Mearns A, Bembridge J. Continuous paravertebral block for post thoracotomy analgesia in children. J Cardiovasc Surg (Torino) 1997;38(5):5436.

4. El-Morsy GZ, El-Deeb A, El-Desouky T, Elsharkawy AA, Elgamal MA. Can thoracic paravertebral block replace thoracic epidural block in pediatric cardiac surgery? A randomized blinded study. Ann Card Anaesth 2012;15(4):259-63.

5. Visoiu M. Outpatient analgesia via paravertebral peripheral nerve block catheter and On-Q pump-a case series. Paediatr Anaesth 2014;24(8):875-8.

6. Visoiu M, Yang C. Ultrasound-guided bilateral paravertebral continuous nerve blocks for a mildly coagulopathic patient undergoing exploratory laparotomy for bowel resection. Paediatr Anaesth 2011;21(4):459-62.

7. Boretsky K, Visoiu M, Bigeleisen P. Ultrasound-guided approach to the paravertebral space for catheter insertion in infants and children. Paediatr Anaesth 2013;23(12):11938.

8. Hall Burton DM, Boretsky KR. A comparison of paravertebral nerve block catheters and thoracic epidural catheters for postoperative analgesia following the Nuss procedure for pectus excavatum repair. Paediatr Anaesth 2014;24(5):51620.

9. Türköz A, Balcı ST, Can Güner M, Ulugöl H, Vuran C, Özker E, et al. Anesthesia management with single injection paravertebral block for aorta coarctation in infant. Paediatr Anaesth 2013;23(11):1078-83. 